\title{
El método científico: la mejor herramienta clínica
}

\author{
Luis Torre-Bouscoulet $\bowtie$
}

Instituto Nacional de Enfermedades Respiratorias Ismael Cosío Villegas, Ciudad de México.

Trabajo recibido: 16-V-2016; aceptado: 24-V-2016

Desde el otoño de 2008 soy profesor titular de los Seminarios de Investigación para Médicos Residentes en el Instituto Nacional de Enfermedades Respiratorias Ismael Cosío Villegas en la Ciudad de México. Ha sido, y ojalá siga siendo, una actividad enriquecedora y divertida. Los residentes de neumología, y algunos otros, presentan sus trabajos de investigación que servirán como su tesis de la especialidad. Un aspecto que he aprendido con los años, común denominador en las generaciones de residentes, es la escisión que existe en su pensamiento entre la medicina clínica y el método científico. Ese pensamiento suele perdurar a lo largo de la vida productiva del médico. Desafortunadamente es común escuchar «yo soy clínico, no investigador». A este respecto mi reflexión.

La palabra "clínica» deriva del griego Kliní, cama, lecho; y hace referencia al proceso mediante el cual el médico llega a un diagnóstico -al pie de la cama del paciente- mediante la historia clínica; es decir, mediante el interrogatorio y el examen físico. Ese ejercicio clínico depende de datos obtenidos de una población.

Es mediante la información generada por la investigación que el clínico logra asociar -integrar- un conjunto de síntomas y signos con un probable diagnóstico nosológico. De forma semejante, la selección del tratamiento e incluso, el pronóstico de los pacientes dependen de la información obtenida de una población de sujetos que comparten atributos; dependen, en una palabra, de la investigación. El clínico, muchas veces sin darse cuenta está aplicando modelos de «probabilidad» que derivan de estudios de investigación. La sospecha clínica se basa precisamente en lo que los estudios de investigación han logrado esclarecer. Por ejemplo, cuando el médico evalúa a un sujeto expuesto a asbesto que desarrolla dolor torácico y disnea progresiva, la sospecha diagnóstica es de mesotelioma. Esa sospecha se basa en que los estudios de investigación han demostrado que los sujetos expuestos a asbesto tienen mayor riesgo de desarrollar mesotelioma y también la investigación es la que ha demostrado que los síntomas más frecuentes son dolor y disnea. ${ }^{1}$ Intuitivamente, el médico está aplicando un conocimiento científicamente establecido en la atención a los pacientes. Así, la práctica clínica tiene a la investigación como su principal ingrediente, de lo contrario no sería medicina. La magia o la alquimia no deben contaminar al ejercicio médico.

Un lugar, tal vez el más legítimo y humano de todos, para observar los fenómenos biológicos, al menos los más aparentes, es al pie de la cama del paciente. Ahí, en el pensamiento y en el juicio del clínico, es donde surgen las preguntas de investigación más relevantes. Recuerdo con ello a Sir. William Osler en aquella fotografía en la que se encuentra sentado a un lado de la cama del paciente, con los codos sobre las rodillas, y soportando su cabeza con la mano izquierda; está «pensando», "observando» a su paciente. ${ }^{2}$ En ese momento es cuando el médico integra el conocimiento científico a otros elementos como la comparación y la experiencia, para obtener una conclusión sobre el diagnóstico y el tratamiento de un paciente. El ejemplo de Sir. William Osler es muy importante, les decía a sus jóvenes colegas «Siempre anote y registre lo inusual. Guarde y compare sus observaciones. Comunique o publique notas breves sobre lo que es llamativo o nuevo». En esas palabras Osler les transmite a sus alumnos lo importante de la investigación clínica. En otro pasaje Osler les decía: «Ver enfermos sin leer libros (o Journals, diríamos ahora; 20 al día, quizá) es como navegar en el mar sin tener cartas de navegación, pero leer libros sin ver enfermos es como nunca navegar». ${ }^{2}$

Al final, lo importante no es la cantidad de información que tenemos -esa podríamos almacenarla en medios electrónicos- lo que no puede ser sustituido es la integración del conocimiento. Esa facultad es, y seguirá siendo, exclusiva del médico. No existe software que integre la información científica disponible con los sín- 
tomas, con las percepciones, con las particularidades de cada paciente, con la contribución relativa de cada problema sobre la totalidad del ente llamado paciente.

Los grandes clínicos son aquellos que mejor integran el conocimiento. Fue la observación y el análisis lo que le permitió a Semelweiss percatarse de que los estudiantes de medicina eran los que -en sus manosllevaban la enfermedad de la sala de disecciones en cadáver a la sala de partos y diseñó, ni más ni menos, que un ensayo clínico controlado en 1847; lavado de manos vs. no lavado de manos y demostró que esa acción tan sencilla prevenía la fiebre puerperal y disminuía la muerte materna a menos del $1 \%{ }^{3}$

El método científico, en el sentido etimológico, significa «Camino hacia el conocimiento». El propósito de la investigación científica es, precisamente, generar conocimiento de forma sistemática, ordenada, metódica, racional y crítica. El método se basa en la observación cuidadosa de los fenómenos, la generación de hipótesis, la implementación de una estrategia experimental $y$, en su caso, en el establecimiento de una teoría científica, un paradigma científico. ${ }^{4}$ Un aspecto central en el proceso de investigación científica es su naturaleza creativa e innovadora. Así, muy ciertas resultan las palabras de Ignacio Chávez al decir; «el médico ayuda por lo que sabe y no por lo que ignora». El médico puede atender al paciente con mucho esmero y dedicación, poniendo en ello toda su capacidad, habilidad, talento y experiencia; sin embargo, si no está presente el conocimiento proveniente del método científico, el médico estará entonces ejerciendo "magia», "protociencia», «alquimia»; pero no medicina.

Otro punto que deseo señalar es que debemos tener precaución con el trillado concepto de «el arte de la medicina». Buena dosis de arte tenía la práctica médica de los maestros que con enorme sensibilidad, hacían diagnósticos precisos sólo con la historia clínica. Sin duda que es arte desarrollar los sentidos al grado de «tocar» el frémito en el área precordial, o de «ver» el signo de Musset en la insuficiencia valvular aórtica, o de "escuchar» la hipersonoridad de una caverna tuberculosa, incluso, de «oler» un absceso pulmonar. Pero hoy no existe, creo, un cardiólogo que tome una decisión sobre la prescripción o tratamiento de alguien a quien le encuentra un frémito sin haber realizado un ecocardiograma; es decir, la tecnología y la investigación van nutriendo a eso a lo que llamamos «clínica». No tengo duda alguna de que existe buena dosis de arte en el ejercicio de la medicina; sin embargo, la línea es delgada y es muy fácil -y cómodo-, disfrazar de «arte» a nuestra ignorancia. Mantengamos a capa y espada, el humanismo y el pensamiento abierto en nuestra profesión; pero no olvidemos que hoy la medicina es más ciencia que arte. La parte más artística de la medicina es, quizás, el manejo de la incertidumbre.

Decía el Dr. Ignacio Chávez: «Clínica fue la medicina al nacer y clínica será siempre por más profunda que sea su transformación científica»; sin embargo, también es cierto, que ese ejercicio clínico debe ser hoy más que nunca, basado en la ciencia, en la evidencia. En el ámbito de la medicina actual el clínico debe saber interpretar, hábilmente, una razón de momios o algún otro indicador de riesgo, probabilidad, asociación, predicción, etc. Si el clínico no sabe interpretar esos -y otros- datos estadísticos, ¿cómo podría extraer las famosas evidencias sobre las que se basa la medicina actual?; la prueba $t, \chi^{2}$ o logrank deben ser tan familiares al clínico como el ritmo de galope o el resultado de una biometría hemática. Tan clínica es la percusión del área hepática como la interpretación de una prueba de ANOVA; ambas ayudan en la toma de decisiones al pie de la cama del paciente; en especial, ahora que tenemos «las evidencias» tan a la mano como nuestro «teléfono inteligente».

\section{REFERENCIAS}

1. Lazarus A, Massoumi A, Hostler J, Hostler DC. Asbestosrelated pleuropulmonary diseases: benign and malignant. Postgrad Med 2012;124(3):116-130. doi: 10.3810/ pgm.2012.05.2555.

2. Young P, Finn BC, Bruetman JE, Emery JD, Buzzi A. William Osler: El hombre y sus descripciones. Rev Med Chile 2012;140:1218-1227.

3. Macdermot HE. Semmelweiss and Holmes. Can Med Assoc J 1912;2(1):24-32.

4. Cruikshank WD. The scientific method in clinical medicine. Br Med J 1946;1(4456):843-844.

\section{$\triangle$ Correspondencia:}

Dr. Luis Torre-Bouscoulet, Subdirector de Investigación Clínica, Instituto Nacional de Enfermedades Respiratorias Ismael Cosío Villegas. Calzada de Tlalpan Núm. 4502, colonia Sección XVI, 14080, Ciudad de México.

Teléfono (52) (55) 54871700 extensión 5160

Correo electrónico: luistorreb@gmail.com

El autor declara no tener conflicto de intereses. 